\title{
Mitigating the effect of COVID lockdown period on Channel and Bandwidth Utilization in Mobile Communication Network in North Western Rajasthan (India)
}

HEMANT PUROHIT ( $\nabla$ hemantpurohit2006@hotmail.com )

JIET https://orcid.org/0000-0002-7933-8439

\section{Parneet Kaur}

Jio Platforms Limited

\section{Shilpa Choudhary}

GL Bajaj Institute of Technology and Management

\section{Research Article}

Keywords: COVID-19 lockdown, COAI , bandwidth, channel utilization, interleaving

Posted Date: March 23rd, 2021

DOl: https://doi.org/10.21203/rs.3.rs-178996/v1

License: (c) (1) This work is licensed under a Creative Commons Attribution 4.0 International License. Read Full License

Version of Record: A version of this preprint was published at Wireless Personal Communications on November 2nd, 2021. See the published version at https://doi.org/10.1007/s11277-021-09300-7. 


\section{Abstract}

The COVID - 19 lockdown has led all the citizens (mobile subscribers) of India to stay at home and rather work from home. The people have started consuming more channel utilization (in mobile communication) through a continuous long duration conversations and more internet data through more streaming content as well as logging on to work from home. It was also reflected in how data demand from residential areas rose as compared to commercial areas. Consequently the bandwidth and channel saturation has evolved out to be a severe problem thereby affecting the work performance of all online offices and multi-national companies. This research paper proposes the simulation based experimental study of DITMC technique for mitigating this effect with a special concern in North Western Rajasthan part of India. The simulation results show that significant enhancement of $60.52 \%$ in channel utilization and bandwidth optimization is possible with negligible overhead of $0.23 \%$. This technique also enables the telecom operators to ponder research in this field that will promisingly lead to manage augmented number of mobile subscribers (independent of any lockdown period) in limited bandwidth thereby using the spectrum efficiently.

\section{Full Text}

Due to technical limitations, full-text HTML conversion of this manuscript could not be completed. However, the latest manuscript can be downloaded and accessed as a PDF.

\section{Figures}




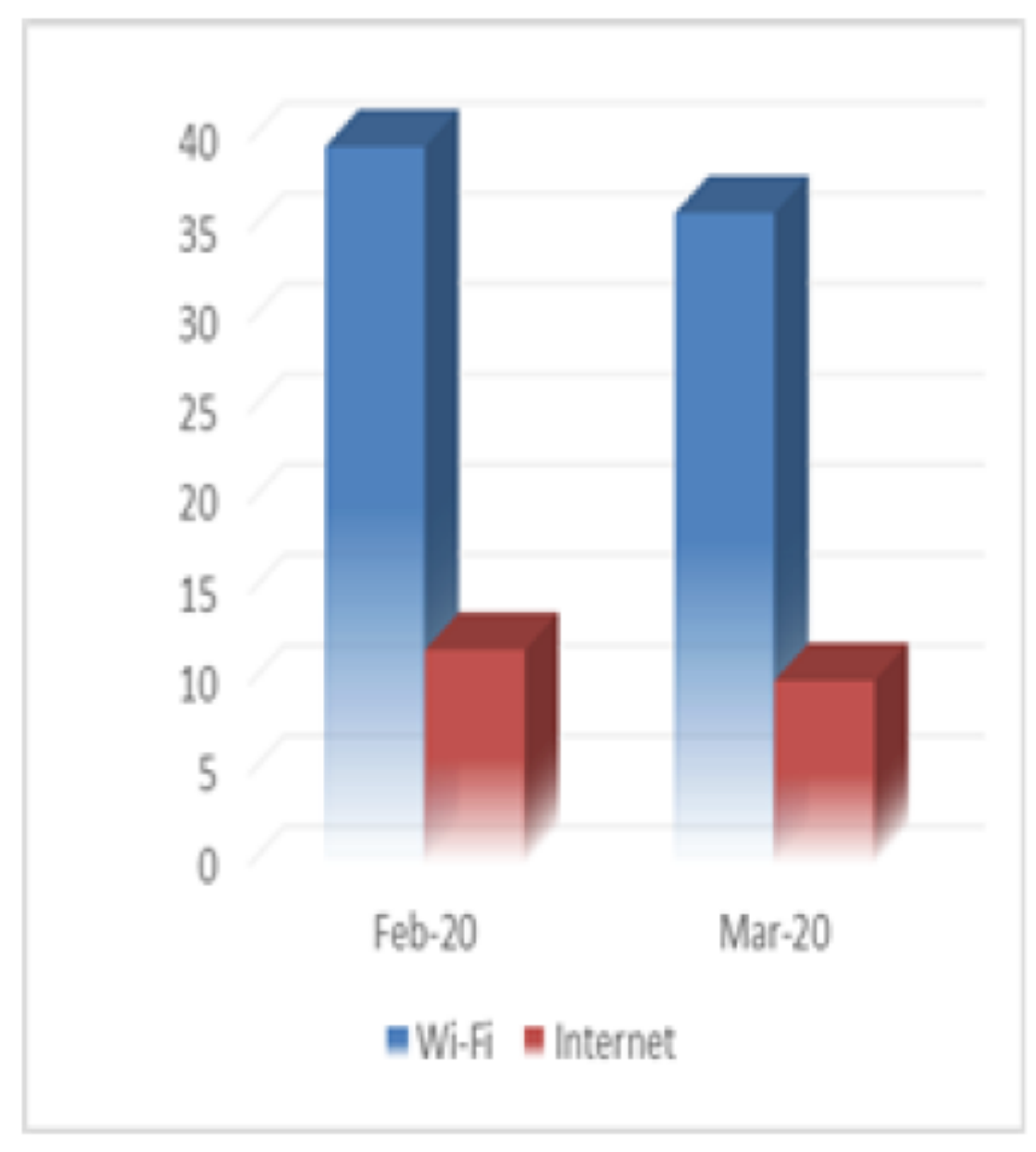

Figure 1

Wi-Fi and Internet Speed (Mbps) [1,22]
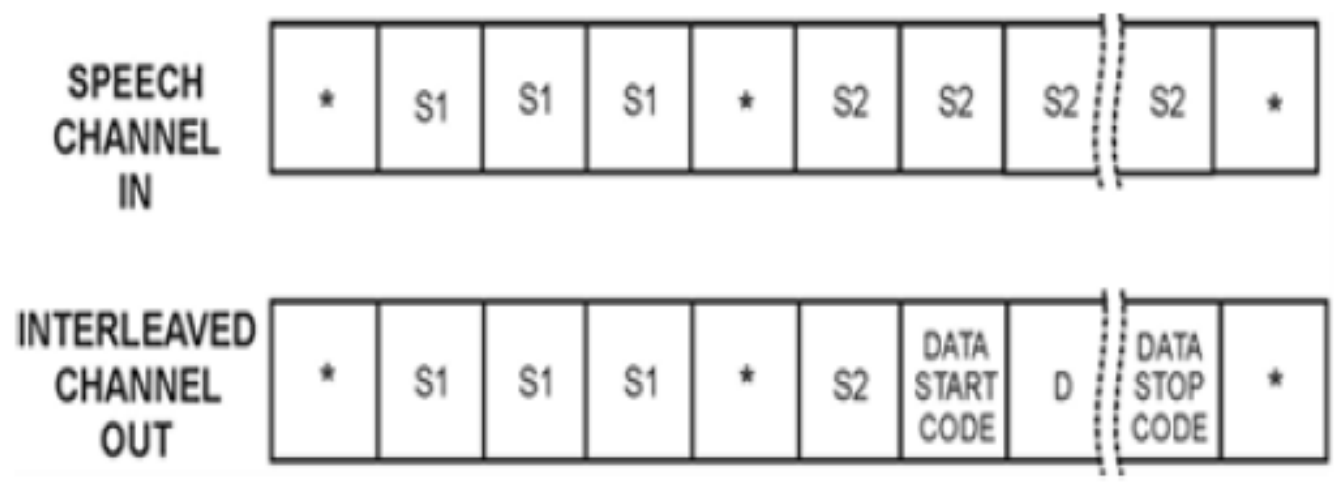

Symbols : S1, S2= Repetitive Speech Bytes

$$
\begin{gathered}
*=\text { Speech Byte }(\mathrm{S}) \\
\mathrm{D}=\text { Data Byte }(\mathrm{S})
\end{gathered}
$$

Figure 2

Concept of Data Interleaving 


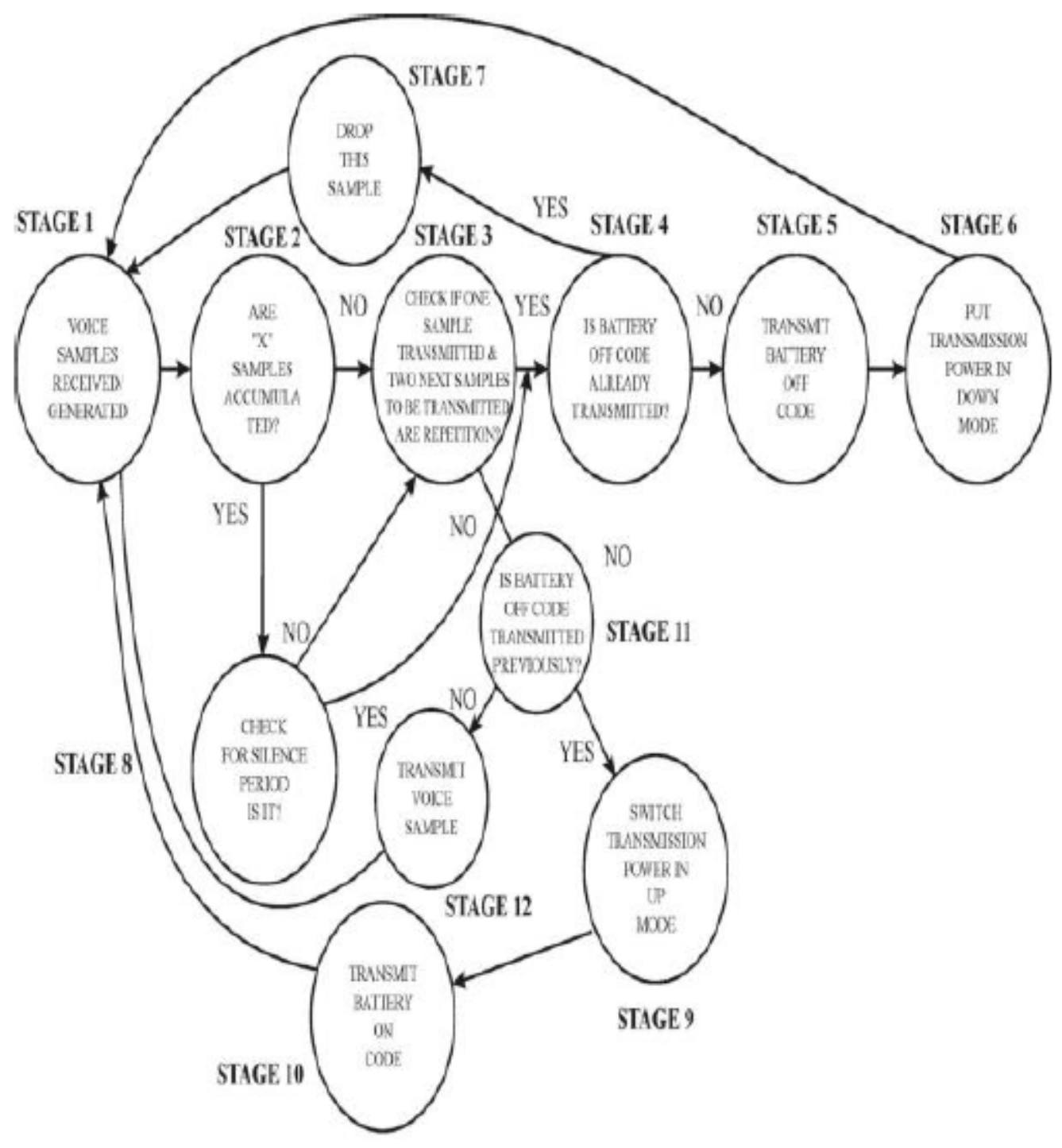

Figure 3

State Transition Diagram for DITMC at mobile station [3] 


\begin{tabular}{|c|c|c|c|c|c|c|c|c|c|c|c|c|c|c|c|c|c|}
\hline $\begin{array}{l}\text { Channel } \\
\text { Allotted to } \\
\text { Voice \& Data }\end{array}$ & 1 & 2 & $\overline{3}$ & $\overline{4}$ & 5 & $\overline{6}$ & 7 & $\overline{8}$ & 9 & 10 & 11 & 12 & 13 & 14 & 15 & 16 & $\begin{array}{l}\text { Number of } \\
\text { data da nnels } \\
\text { (due to } \\
\text { interleaving) }\end{array}$ \\
\hline $\begin{array}{l}\text { Channel } \\
\text { avilable for } \$ 1\end{array}$ & V & $\bar{V}$ & V & $\bar{D}$ & $\bar{D}$ & $\overline{0}$ & V & V & $\bar{V}$ & $\bar{D}$ & $\bar{D}$ & $\bar{D}$ & $\bar{D}$ & $\bar{D}$ & V & $\bar{D}$ & 9 \\
\hline $\begin{array}{l}\text { Channel } \\
\text { avalable for } \$ 2\end{array}$ & V & V & I & D & $D$ & 0 & I & V & V & D & D & D & 0 & D & V & 0 & 11 \\
\hline $\begin{array}{l}\text { Channel } \\
\text { avalablefor } 53\end{array}$ & V & 1 & $I$ & $D$ & $D$ & 0 & V & I & I & D & D & D & D & $D$ & V & $D$ & 13 \\
\hline $\begin{array}{l}\text { Channel } \\
\text { avalable for } \$ 4\end{array}$ & V & 1 & V & $D$ & $D$ & 0 & I & I & V & 0 & 0 & $D$ & D & $D$ & V & 0 & 12 \\
\hline $\begin{array}{l}\text { Channel } \\
\text { avalablefor\$5 }\end{array}$ & V & V & V & $D$ & D & $D$ & V & V & V & D & D & D & D & D & V & $D$ & 09 \\
\hline $\begin{array}{l}\text { Channel } \\
\text { valable for } 56\end{array}$ & 1 & $T$ & $T$ & 0 & 0 & 0 & 1 & I & I & 0 & 0 & 0 & D & D & 1 & 0 & 15 \\
\hline $\begin{array}{l}\text { Channel } \\
\text { avalablefor } \$ 7\end{array}$ & V & 1 & I & D & $D$ & 0 & I & V & I & 0 & D & D & D & D & 1 & D & 14 \\
\hline $\begin{array}{l}\text { Channel } \\
\text { avaiable for } \$ 8\end{array}$ & V & V & V & $D$ & $D$ & 0 & V & V & I & 0 & 0 & 0 & D & D & V & 0 & 10 \\
\hline
\end{tabular}

\section{Figure 4}

Increased channels for data due to the data interleaving concept. V: voice channel, I: interleaved channel available for data traffic, D: data channel [7] 


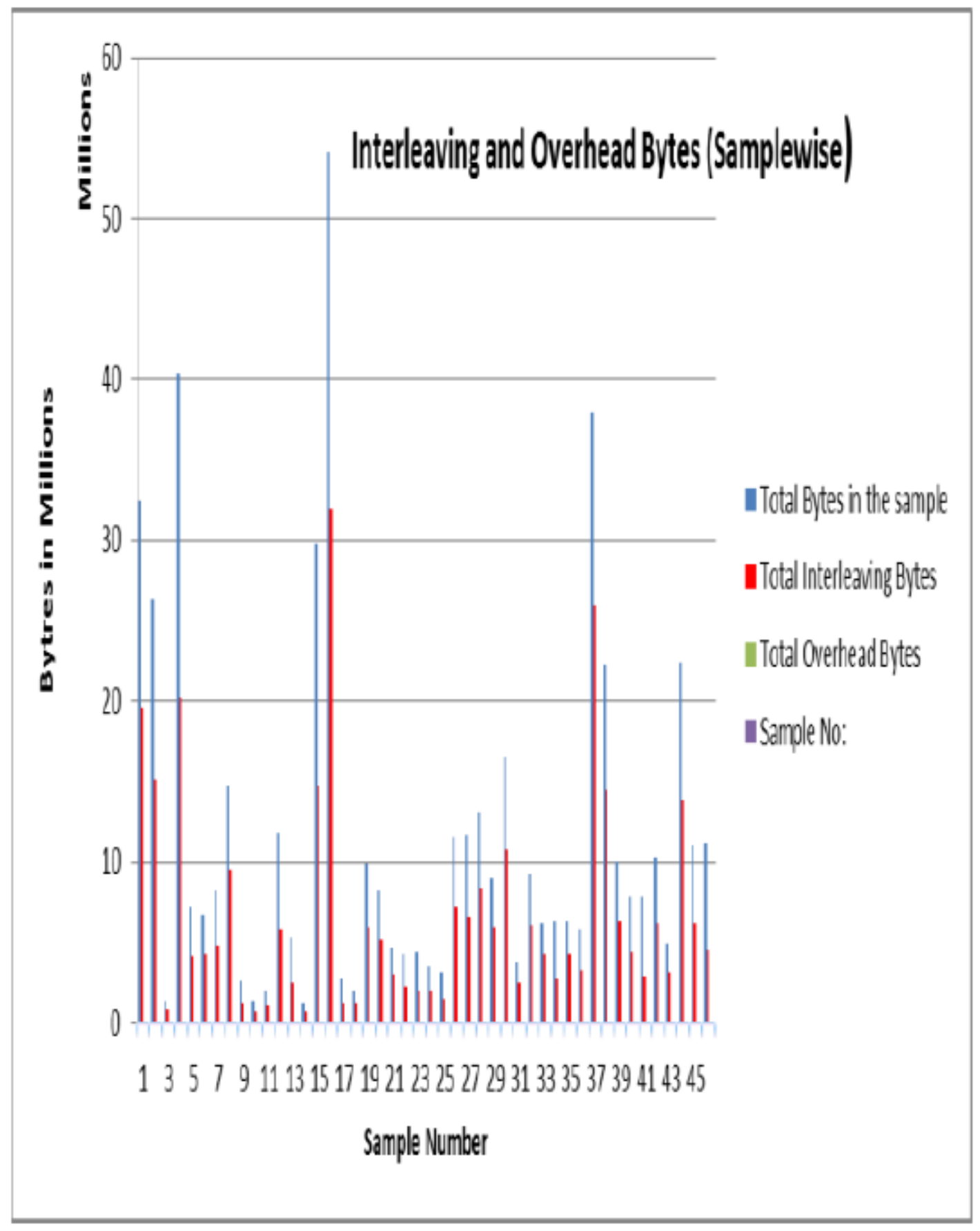

Figure 5

Interleaving and Overhead Bytes v/s samples 


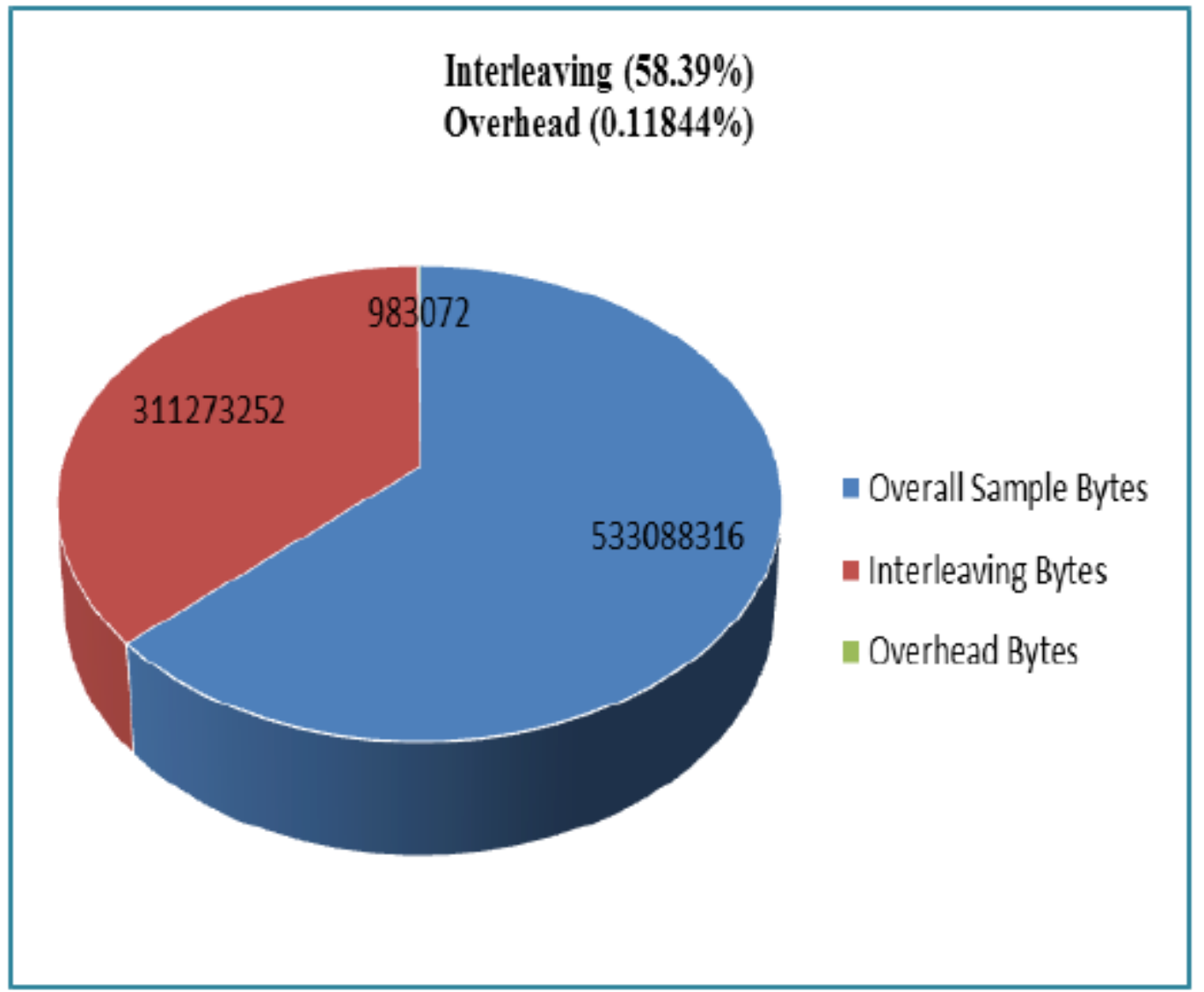

Figure 6

Interleaving, Overhead and Overall samples (in \%) 